\title{
Snaps, Selfies, and Shares: How Three Popular Social Media Platforms Contribute to the Sociocultural Model of Disordered Eating Among Young Women
}

\author{
Jessica F. Saunders, MS, ${ }^{1, *}$ and Asia A. Eaton, $\mathrm{PhD}^{1}$
}

\begin{abstract}
The current study aimed to integrate and test the sociocultural model of disordered eating with theories explaining the impact of mass media on the development of disordered eating for users of three popular social networking platforms. Young women social networking site (SNS) users (age 18-24) who had never received an eating disorder diagnosis $(N=637)$ completed questions capturing their SNS gratifications and usage, body surveillance, social comparisons, body dissatisfaction, and eating pathology. Measures were administered in one online session. Model relationships were similar across users of all three SNS platforms: Facebook, Instagram, and Snapchat. Users of all platforms demonstrated a significant positive relationship between upward comparisons and disordered eating outcomes, and between body surveillance and disordered eating outcomes, although differences between models did emerge. Empirical findings support extending the sociocultural model of disordered eating to include SNS uses and gratifications.
\end{abstract}

Keywords: social comparison, self-objectification, SNS, disordered eating, body dissatisfaction

\section{Introduction}

$\mathbf{S}_{\mathrm{s}}^{\mathrm{o}}$ OCIOCULTURAL PRESSURES FOR thinness and the internalization of the thin ideal consistently emerge as robust predictors of disordered eating outcomes in young women. ${ }^{1-4}$ These pressures increase social-cognitive processes focused on appearance, such as body-related comparisons, body surveillance, and attention bias toward thinness, with cascading influences on disordered eating outcomes. ${ }^{1,5,6}$ To date, the existing measures to quantify body-related comparisons and body surveillance have been developed and normed for female samples. The relationship between sociocultural pressures for thinness, social-cognitive processes, and disordered eating outcomes among women can be understood by integrating several social psychology theories. ${ }^{3}$ Social comparison, objectification, cultivation, and gratifications and uses theories overlap to form a nexus of influence that explains the perpetuation of disordered eating among women in Western culture. ${ }^{3}$

Social comparison theory ${ }^{7}$ posits that individuals engage in comparisons with similar others to acquire self-knowledge in a given domain. The existing literature highlights a strong relationship between engaging in upward appearance-related comparisons (i.e., using an idealized individual as a target) and higher levels of body dissatisfaction. ${ }^{8,9}$ In contrast, downward appearance-related comparisons (i.e., using a less idealized individual as a target) were once thought to protect against body dissatisfaction by increasing self-esteem and well-being. ${ }^{10,11}$ However, empirical tests found downward comparisons to be either unrelated to body satisfaction and eating pathology, ${ }^{12,13}$ or predictive of higher eating and shape concerns. ${ }^{14}$ Prior correlational research suggests that downward comparisons have the strongest impact on disordered eating outcomes when experienced in conjunction with upward comparisons. ${ }^{15}$

Along with social comparisons, the expanded sociocultural model of disordered eating ${ }^{1}$ identifies body surveillance, or the tendency to over-focus on appearance attributes, ${ }^{16-19}$ as a social-cognitive factor linking sociocultural pressures to disordered eating. By adopting an observer perspective and internalizing messages regarding the malleability of one's body, self-objectification primarily manifests behaviorally through body surveillance. ${ }^{20}$ Women who are concentrated on their appearance are also more

\footnotetext{
${ }^{1}$ Department of Psychology, Florida International University, Miami, Florida.

*Current address: Women's Research Institute of Nevada, University of Nevada, Las Vegas, Las Vegas, Nevada.
} 
observant of how they compare with other women; thus, body surveillance tendencies predict disordered eating tendencies, and this relationship is linked by appearance-related comparisons. $^{2}$

One of the ways sociocultural appearance norms are disseminated is through media, including SNS platforms. While social networking sites (SNS) can improve one's well-being by strengthening weak social ties, ${ }^{21}$ promoting group identity, ${ }^{22}$ and offering support unavailable offline, ${ }^{23}$ the recent proliferation of SNS platforms also brings increased opportunities to partake in appearance-related comparisons ${ }^{24}$ and to objectify the self and others. ${ }^{25}$

Cultivation and gratifications and uses theories, the final two theories used to explain the cultural manifestation of eating disorders (EDs) in young women, ${ }^{3}$ describe how media effects viewers and how viewers engage with media, respectively. Cultivation theory posits that increased media exposure causes people to believe that the ideals portrayed in media exist in the real world, ${ }^{26}$ and gratifications and uses theory describes the needs that drive individuals to seek out mass media. ${ }^{27}$ Based on these theories, exposure to the thin ideal and other harmful norms around appearance through SNS will convince individuals that these are appropriate realworld standards, leading to objectified body consciousness and social comparisons.

\section{SNS and Disordered Eating Among Young and Emerging Adults}

Emerging adulthood ${ }^{28}$ or the new adolescence ${ }^{29}$ is a developmental period for not just increased body dissatisfaction and disordered eating ${ }^{30}$ but also for increased social media use. ${ }^{31}$ For young and emerging adults, Snapchat, Instagram, and Facebook are the most popular SNS in the United States. ${ }^{32-34}$ To date, the majority of the research concerning SNS and body dissatisfaction outcomes has focused on Facebook and Instagram. Studies using these platforms have highlighted the correlations between time spent on SNS, ${ }^{35,36}$ frequency of engagement, ${ }^{37}$ or number of Facebook friends ${ }^{38,39}$ and body dissatisfaction and disordered eating outcomes. ${ }^{40}$

Disordered eating and clinical EDs are prevalent in the United States; nearly $13 \%$ of girls and women experience a clinical or subclinical ED in their lifetime. ${ }^{41}$ The EDs classified in the DSM-5, anorexia nervosa (AN), bulimia nervosa $(\mathrm{BN})$, binge eating disorder (BED), and other specified feeding or eating disorders (OSFED), overlap in correlates, risk factors, and component symptoms. ${ }^{42}$ Common to all EDs are body dissatisfaction, weight concerns, overevaluation of shape and weight, binge eating and emotional eating (although less common in AN), compensatory behaviors to counteract the perceived possible weight gain from eating, dietary restriction, and low weight status (although less common in BED). ${ }^{4}$ EDs are considered the most lethal of all mental illnesses, ${ }^{43}$ and numerous theoretical models have attempted to explain how disordered eating develops in emerging adult women. ${ }^{1-3}$

Time spent using SNS and frequency of media exposure both correspond with the sociocultural influences featured in the expanded sociocultural model of disordered eating. As depicted in Figure 1, sociocultural influences lead to internalization of the thin ideal, with social comparison and body

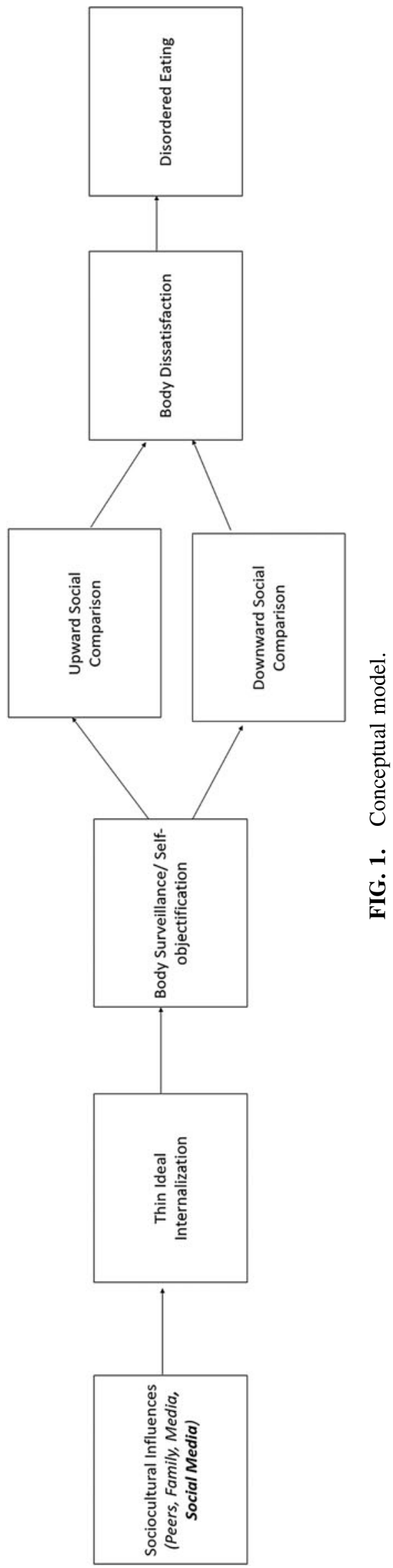


surveillance serving as mediators within the model. In this model, we have positioned body surveillance before social comparisons, consistent with prior claims that body awareness stimulates the desire to compare. ${ }^{2}$ Time spent engaging with SNS has been associated with nearly all aspects of the sociocultural model of disordered eating, including higher levels of thin-ideal internalization, appearance-related comparisons, body surveillance, and body dissatisfaction. ${ }^{35,36}$

While use of the aforementioned SNS platforms demonstrates consistent main effects on disordered eating outcomes among young women, Perloff ${ }^{24}$ recognized that these main effects may disguise more nuanced relationships depending on the reasons individuals are consuming SNS. Based on uses and gratifications theory, some individuals may be actively engaging with SNS for the express purpose of obtaining information on appearance and eating behaviors, while others may be using SNS for other reasons (e.g., work purposes). Both groups of individuals may be exposed to opportunities for appearance-related comparisons and selfobjectification; the former group is likely at a greater risk for engaging in these social-cognitive processes. Thus, Perloff ${ }^{24}$ proposed an extension to the sociocultural model of disordered eating that integrates uses and gratifications theory as a way to predict who will be most affected by SNS engagement.

This extension has been empirically tested in a handful of more refined examinations of Facebook activities, above and beyond sheer time spent on the platform. Participants who shared "status updates" seeking negative feedback were more likely to report weight, shape, and disordered eating concerns than participants who used neutral or positive language when sharing information on Facebook. ${ }^{44}$ Likewise, the tendency to share and view more photos of others on Facebook correlates with objectified body consciousness, internalization of the thin ideal, and body dissatisfaction. ${ }^{45}$

Little research to date, however, has examined the relationship between Snapchat and the elements of the sociocultural model of body dissatisfaction and disordered eating, despite the fact that Snapchat is currently the most popular and most "important" SNS for teens and young adults in the United States. ${ }^{33,34}$ Very recent research relates the use of highly visual social media, such as Instagram and Snapchat, as correlates of body image concerns in adolescents ${ }^{46}$ and sexual minority men. ${ }^{47}$ More photos are exchanged each day via Snapchat than on Facebook and Instagram combined, ${ }^{48}$ and the ephemeral status of the images shared through the Snapchat platform distinguishes it from the other SNS aimed at documenting life events. ${ }^{49}$ Snapchat is thought to cultivate close $^{50}$ rather than weak ties, as users typically interact with smaller social networks via this medium. ${ }^{51}$ Compared to text-based SNS, Snapchat is associated with greater happiness and connection, ${ }^{52}$ and Snapchat users are more likely to value social capital than nonusers. ${ }^{53}$

However, not all research finds a positive impact of Snapchat on mental health. According to a 2017 report, ${ }^{54}$ SNS use is linked to mental health risks, including increased levels of anxiety, depression, and body dissatisfaction. When the net impact of each of these dimensions was aggregated and ranked, Instagram and Snapchat were found to have the greatest and second-greatest negative net impact on wellbeing. ${ }^{54}$ In conclusion, the overall effect of Snapchat on user health and well-being is unclear, as some studies find
Snapchat associated with more negative outcomes than textbased SNS, ${ }^{52}$ and other studies find Snapchat being associated with more positive outcomes than text-based SNS. ${ }^{54}$

\section{Current Study}

The current study aimed to further test Perloff' ${ }^{24}$ integration of uses and gratifications theory into the sociocultural model of disordered eating with the three most popular SNS among young adults: Facebook, Instagram, and Snapchat. We aimed to understand what aspects of SNS use and what SNS platforms most related to body dissatisfaction and disordered eating outcomes and their social-cognitive antecedents among young women. Building from Perloff's ${ }^{24}$ theoretical model and the previously tested structural equation models, ${ }^{1,2}$ we developed the model featured in Figure 2. Within our proposed model, we expected one's social media negativity rating to be predictive of the social-cognitive constructs of body surveillance, upward comparison, and downward comparison. This decision was made given the individual vulnerability factors thought to precede with these constructs (i.e., low self-esteem, depression, perfectionism, and centrality of appearance to self-worth $)^{24}$; the social media negativity construct served as a holistic link between these individual vulnerability factors and the mediating social-cognitive processes. Next, we anticipated body surveillance would positively relate to upward comparison tendencies, which would have positive relationships with disordered eating outcomes. Our inclusion of downward appearance-related comparison was exploratory, given that prior work has found downward comparison to correlate with body dissatisfaction and disordered eating in certain contexts and for particular populations. ${ }^{12,14}$

We allowed the error variance of the disordered eating outcomes to correlate, as these behaviors often occur in tandem. ${ }^{55}$ Given the divergent uses of Facebook compared with both Instagram and Snapchat, ${ }^{56}$ we examined differences in how the proposed model operates based on the primary platform used by participants. We hypothesized that the model relationships would be present regardless of platform, as SNS are one of multiple venues for social comparison and body surveillance. We anticipated model relationships would be stronger for Instagram and Snapchat users than Facebook users, as the highly filtered, imagebased nature of Instagram and Snapchat likely encourages more body-focused social cognitive processes.

\section{Methods}

\section{Procedure}

After providing informed consent, participants completed the standardized assessments and provided demographic information via the secure Qualtrics platform. Recruitment occurred via the Department of Psychology undergraduate research participation system, in which Psychology students receive course extra credit in exchange for participation. Participation was open to female, daily SNS users between the ages of 18-24 who had never received a clinical ED diagnosis. Procedures were approved by the university IRB.

\section{Participants}

The final sample $(N=637)$ was ethnically diverse $(67.5 \%$ Hispanic white, $12.4 \%$ non-Hispanic white, $12.6 \%$ black, 


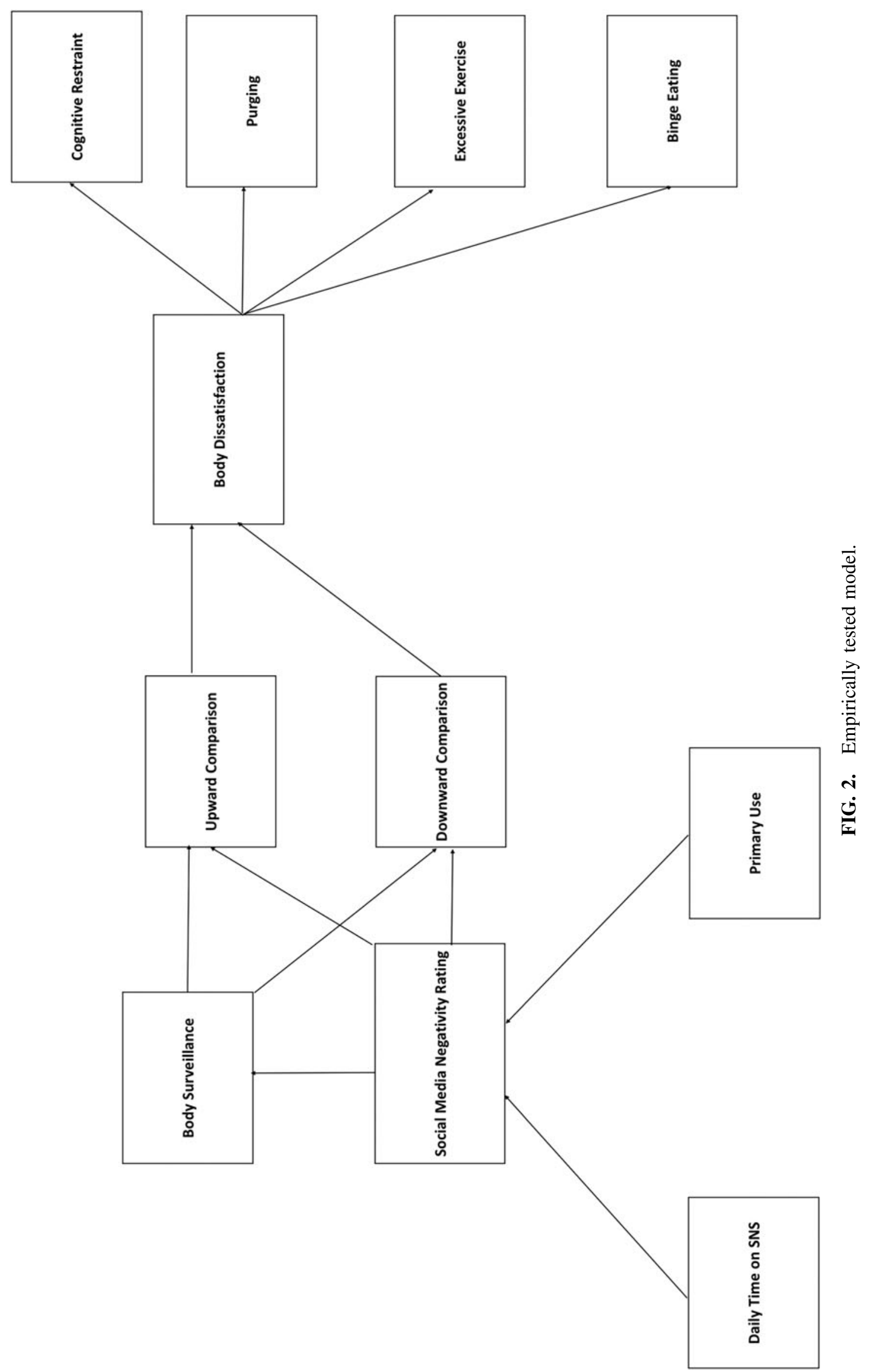


2.5\% Asian, $3.5 \%$ multiracial, and $1.6 \%$ self-identified as other), reporting a mean age of 21.3 years $(S D=1.72$; see footnote a for exclusion criteria).

\section{Measures}

Participants completed the standardized measures outlined in Table 1. ${ }^{16,57,58}$ To quantify SNS uses and gratifications, participants answered a series of questions about their SNS use. At the time of data collection, there was no existing standardized measure of SNS uses and gratifications. Therefore, the authors developed a set of questions on SNS uses and gratifications from existing qualitative research on the topic. ${ }^{59}$ These questions were pilot-tested with female undergraduate students. The final set of four questions and their coding scheme appear in Table 2. The free response item was coded by the first author; $60 \%$ of the responses were independently coded by an undergraduate research assistant for reliability $(\boldsymbol{\kappa}=0.9)$.

\section{Analytic plan and data screening}

Preliminary analyses were conducted using SPSS 23.0, and the subsequent path analysis was conducted using AMOS 21.0. Given the fraction of missing data $(0.0006 \%)$, these values were mean imputed. ${ }^{60}$ Preliminary descriptive and inferential analyses (MANOVA and chi-square) were conducted to examine group-level differences in social comparison, body surveillance, and disordered eating outcomes and differences in the distribution of categorical responses, and to ensure empirical support of our planned model. Multiple fit indices were used to thoroughly evaluate global model fit, with the acknowledgment that one fit statistic below the established cutoff does not indicate poor model fit. ${ }^{61}$

Data were analyzed via multigroup path analysis. The structural invariance of the model across the three groups (Facebook, Instagram, and Snapchat) was evaluated by testing an unconstrained model, with freely estimated parameters. The fit of the unconstrained model was compared with a constrained model in which the paths were forced to be equal across groups. A $\chi^{2}$ difference test, using the $\chi^{2}$ test statistic from the respective models, examined whether the model fits the data significantly better when the paths were freely estimated compared with when the paths were constrained.

\section{Results}

Within the sample, $15.1 \%$ of participants endorsed $\mathrm{Fa}$ cebook, 33.6\% endorsed Snapchat, and 51.3\% endorsed Instagram as the platform they used most frequently. These results align with recent findings from a young adult sample in the United Kingdom. ${ }^{54}$ Participants reported seeking connection at similar rates across the three platforms, yet were significantly more likely to primarily use Instagram or Snapchat rather than Facebook for entertainment and to survey others, and significantly more likely to use Instagram for the purposes of being seen by others, compared with both Facebook and Snapchat (see footnote b).

\section{Path analyses}

Multiple fit indices for the hypothesized model point to relatively good model fit (RMSEA $=0.04,90 \%$ CI $[0.032$ $0.047], p$-close test of model fit $=0.988, \mathrm{CFI}=0.931, \mathrm{TLI}=$ $0.871)$; no theoretically meaningful modification indices were suggested. The fit of the model degraded significantly when the paths were constrained, $\Delta \chi^{2}(26)=47.64$, $p<0.006$, supporting the hypothesis that the strength of the model relationships would differ across the three SNS. The standardized path coefficients for each SNS appear in Figures 3-5.

Participants' overall SNS experience rating was significantly related to each of the social-cognitive mediators in the sociocultural model of disordered eating. These relationships patterned differently across the three SNS. A highly negative SNS experience was related to a greater tendency to engage in downward comparison for participants who endorsed Facebook as their primary SNS $(\beta=0.24, B=2.45, \mathrm{SE}=0.95$,

Table 1. Standardized Measures Administered

\begin{tabular}{|c|c|c|c|}
\hline Scale & Sample items & Scoring & Reliability \\
\hline $\begin{array}{l}\text { Upward and downward } \\
\text { appearance comparison } \\
\text { scale (UPACS and } \\
\text { DACS) }\end{array}$ & $\begin{array}{l}\text { Upward: "When I see good } \\
\text { looking people, I wonder } \\
\text { how I compare to them." } \\
\text { Downward: "I tend to compare } \\
\text { my physical appearance } \\
\text { with people whose bodies } \\
\text { are not as physically } \\
\text { appealing."" }\end{array}$ & $\begin{array}{l}\text { 5-point Likert scale; responses } \\
\text { summed and averaged to } \\
\text { produce mean score for each } \\
\text { subscale. Higher scores } \\
\text { reflective of greater tendency } \\
\text { to engage in comparison. }\end{array}$ & $\begin{array}{l}\text { UPACS } \alpha=0.93, \text { DACS } \\
\quad \alpha=0.94\end{array}$ \\
\hline $\begin{array}{l}\text { Body surveillance subscale } \\
\text { of the objectified body } \\
\text { consciousness scale } \\
(\text { OBCS })^{16}\end{array}$ & $\begin{array}{l}\text { "During the day, I think } \\
\text { about how I look many } \\
\text { times." }\end{array}$ & $\begin{array}{l}\text { 7-point Likert scale; higher } \\
\text { scores indicate higher } \\
\text { levels of body surveillance. }\end{array}$ & $\alpha=0.80$ \\
\hline $\begin{array}{l}\text { Body dissatisfaction, cognitive } \\
\text { restraint, binge eating, } \\
\text { purging, and excessive } \\
\text { exercise subscales of the } \\
\text { eating pathology symptoms } \\
\text { inventory (EPSI) }\end{array}$ & $\begin{array}{l}\text { "I stuffed myself with food to } \\
\text { the point of feeling sick.", }\end{array}$ & $\begin{array}{l}\text { 5-point Likert scale; higher } \\
\text { scores indicate higher } \\
\text { levels of body dissatisfac- } \\
\text { tion and disordered eating. }\end{array}$ & $\begin{array}{l}\text { Body dissatisfaction } \\
\alpha=0.85, \text { cognitive } \\
\text { restraint } \alpha=0.75 \text {, binge } \\
\text { eating } \alpha=0.85 \text {, purging } \\
\alpha=0.84, \text { and excessive } \\
\text { exercise } \alpha=0.82\end{array}$ \\
\hline
\end{tabular}


Table 2. Social Media Uses and Gratifications Questions Administered

\begin{tabular}{lc}
\hline Question & \multicolumn{1}{c}{ Response options } \\
\hline $\begin{array}{l}\text { Which social media platform do you use most } \\
\text { frequently? }\end{array}$ & $\begin{array}{c}\text { Facebook, Instagram, Snapchat, other (those who selected other } \\
\text { were excluded from analyses) }\end{array}$ \\
$\begin{array}{l}\text { What is the main reason you use (primary social } \\
\text { media platform?) }\end{array}$ & $\begin{array}{c}\text { Free responses were coded by two research assistants into the } \\
\text { following four categories: (1) connection, (2) entertainment } \\
\text { and boredom, (3) news and surveillance, (4) to be seen by } \\
\text { others }\end{array}$ \\
$\begin{array}{l}\text { How much time do you spend, in total, on social } \\
\text { media per day? }\end{array}$ & $\begin{array}{c}\text { (1) Less than 30 minutes, (2) 30 minutes to } 1 \text { hour, } \\
\text { (3) } 1-2 \text { hours, (4) } 2-3 \text { hours, (5) more than } 3 \text { hours per day }\end{array}$ \\
$\begin{array}{l}\text { Overall, how would you rate your day-to-day social } \\
\text { media experience? }\end{array}$ & $\begin{array}{c}\text { (1) Very positive, (2) positive, (3) neutral, (4) negative, (5) very } \\
\text { negative }\end{array}$
\end{tabular}

$p=0.01)$, whereas for Instagram and Snapchat users, a highly negative SNS experience was predictive of a greater tendency to engage in upward comparison (Instagram $\beta=0.10$, $B=1.20, \mathrm{SE}=0.59, p=0.031$; Snapchat $\beta=0.17, B=2.23$, $\mathrm{SE}=0.70, p<0.001)$ and body surveillance (Instagram $\beta=0.25, B=2.23, \mathrm{SE}=0.48, p<0.001$; Snapchat $\beta=0.26$, $B=2.24, \mathrm{SE}=0.60, p<0.001)$. Downward comparison tendencies were predictive of body dissatisfaction levels for the Facebook $(\beta=0.22, B=0.24, \mathrm{SE}=0.05, p=0.02)$ and Snapchat users $(\beta=0.13, B=0.12, \mathrm{SE}=0.06, p=0.048)$, but not for participants spending the majority of their SNS time on Instagram ( $\beta=0.01, B=0.01 \mathrm{SE}=0.48, p=0.92)$.

Regardless of platform endorsed, the links between upward comparison, body dissatisfaction, and disordered eating remained robust, replicating prior sociocultural models of disordered eating. ${ }^{1,3,5}$ Also, similar to prior findings, the links between body dissatisfaction and binge eating are stronger than those between body dissatisfaction and other disordered eating behaviors. ${ }^{62}$ The models explained between $29 \%$ and $35 \%$ of the variance in binge eating behaviors, $26-31 \%$ of the variance in body dissatisfaction, $15-35 \%$ of the variance in purging behaviors, $6-10 \%$ of the variance in cognitive restraint, and $2-12 \%$ of the variance in excessive exercise behaviors.

\section{Discussion}

The current study sought to integrate the expanded sociocultural model of disordered eating ${ }^{1,2}$ with social psychological theories explicating the relationship between media use and disordered eating outcomes. This integrated model was examined for three different groups of young women SNS users: those who primarily used Facebook, Instagram, and Snapchat. This was also the first study to measure both upward and downward comparisons in the expanded sociocultural model of disordered eating, and to examine the effects of Snapchat. One-third of participants endorsed Snapchat as their primary SNS platform, highlighting the need for this investigation. No study to date has examined the differential impact of image-focused SNS compared with less image-centered mediums on body dissatisfaction and disordered eating through social-cognitive pathways. We replicated and extended the prior research regarding SNS, social-cognitive constructs, and disordered eating outcomes. ${ }^{25,35}$
Some differences across models emerged. Contrary to our predictions, the model fit differently across each of the SNS (Instagram, Snapchat, and Facebook), with the model of Instagram users explaining the least amount of variance in the constructs. Relatedly, Facebook and Snapchat explained more variance in both upward and downward comparisons than Instagram, although only Facebook users demonstrated a significant relationship between downward comparison and body dissatisfaction. Therefore, Facebook users showed the most consistent relationship between the overall use of comparisons (both upward and downward) via SNS and eating disordered outcomes.

The impact of the SNS negativity rating was also most profound for the groups of participants who endorsed Instagram or Snapchat as their primary SNS. That is, subjectively negative experiences on Instagram or Snapchat impacted body dissatisfaction through social-cognitive processes of social comparison and body surveillance, as theorized by Perloff. ${ }^{24}$ Gratifications sought from SNS engagement, which tend to vary slightly based on SNS, indirectly increase body dissatisfaction and disordered eating behaviors in young women. Users of Instagram and Snapchat reporting an overall highly negative SNS experience also had a greater tendency toward body surveillance and upward appearance-related comparison. As predicted, body surveillance was a more integral part of the model for Instagram and Snapchat users compared with Facebook users. The model for Facebook users did not explain any of the variance in body surveillance. This finding likely speaks to the content viewed on Instagram and Snapchat being more appearance focused.

This nuanced extension of the sociocultural model of disordered eating highlights unique contributions of the three most common social media platforms on disordered eating outcomes, and reinforces the role body dissatisfaction plays in robustly predicting disordered eating outcomes. Across all three platforms, there were very strong relationships between body dissatisfaction and binge eating, purging, and cognitive restraint. These behaviors put an individual most at risk for developing a clinical ED, ${ }^{62}$ and highlight the validity of the previously empirically examined model. ${ }^{1,2,5}$ Moreover, the relationship between body dissatisfaction and excessive exercise was statistically significant for all groups, but stronger for the Facebook and Instagram groups compared with the Snapchat group. This 


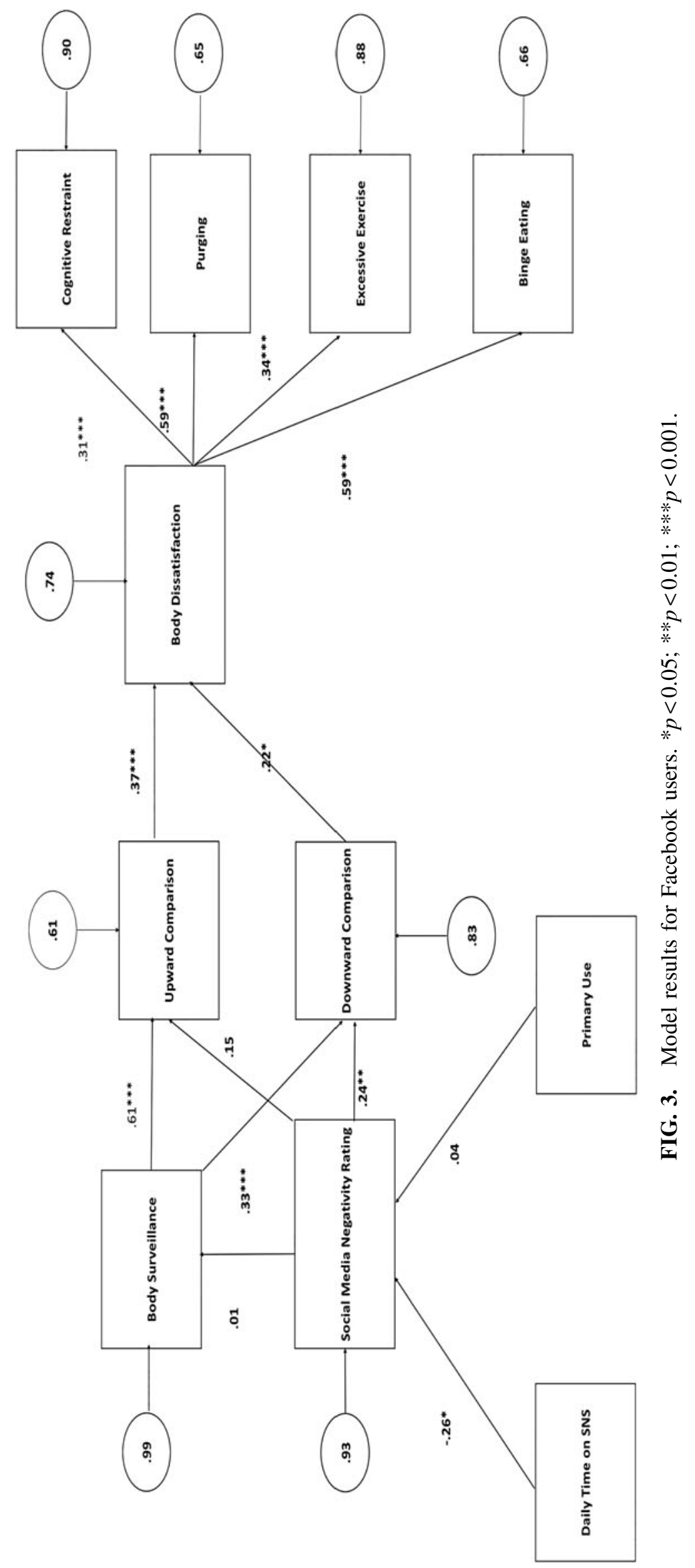




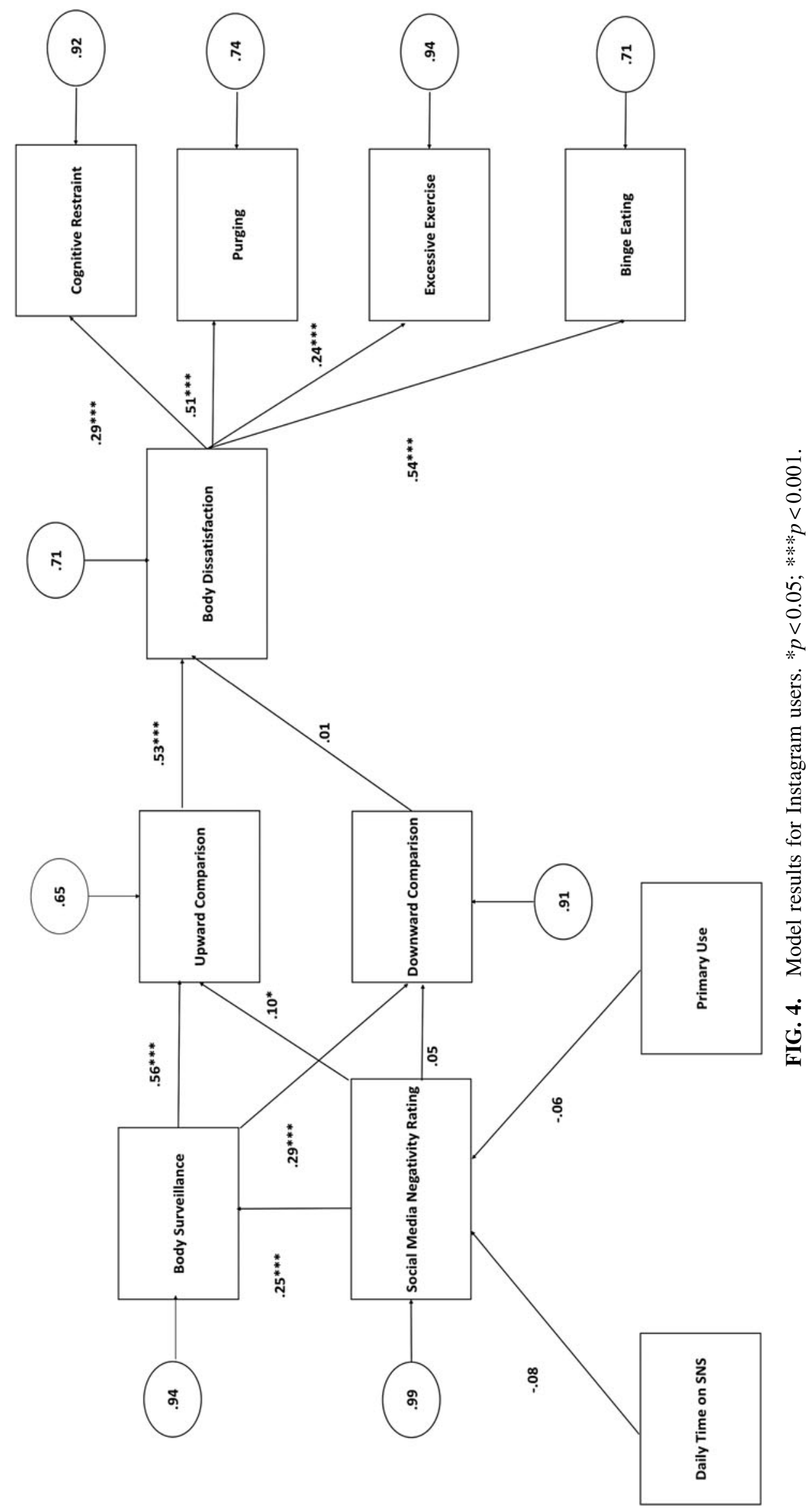




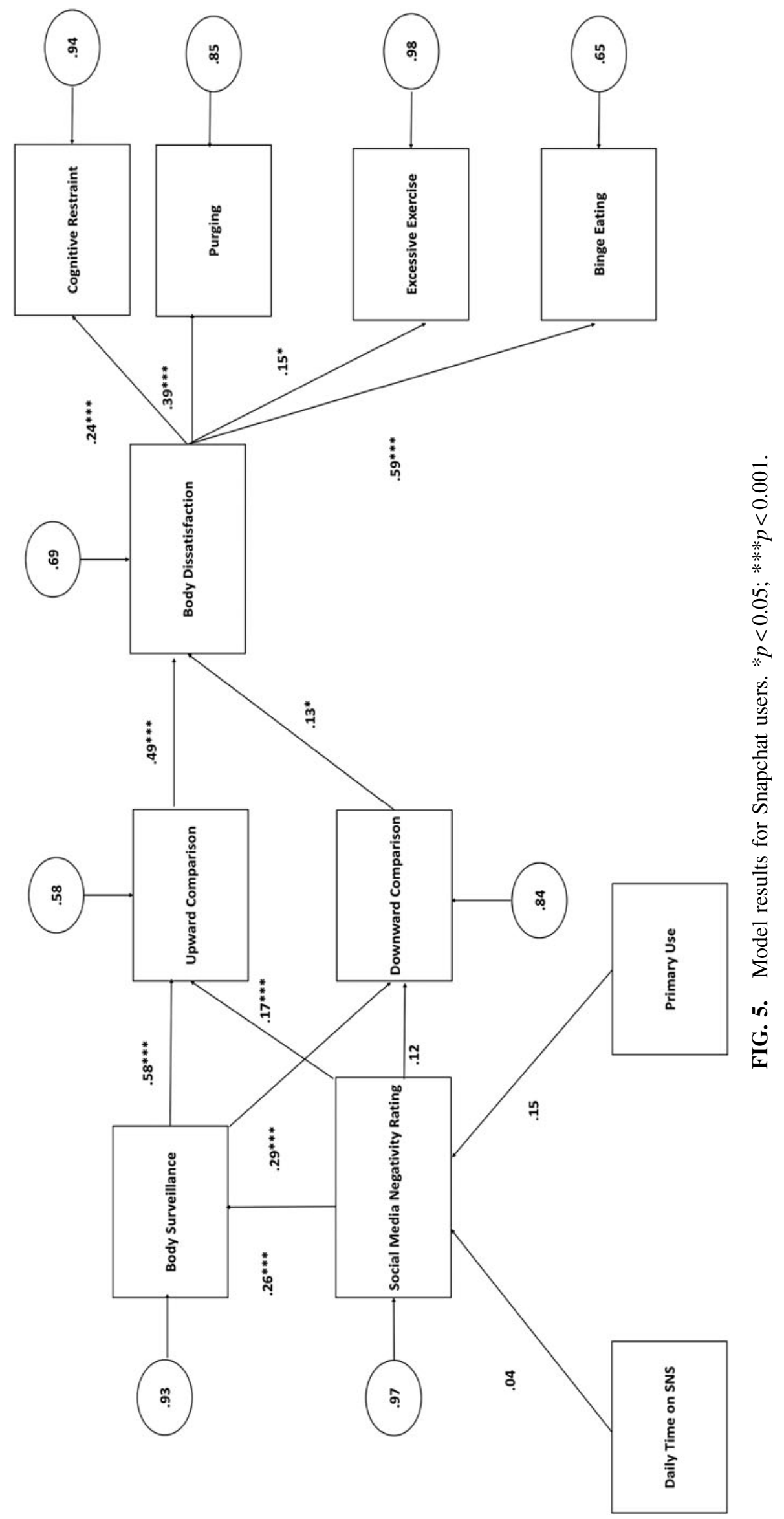


might speak to the exercise status updates or images users share on these two platforms. ${ }^{63}$

Ultimately, these findings serve to inform future body dissatisfaction and ED prevention and intervention programs. McLean and colleagues ${ }^{64}$ implemented a pilot study of an SNS literacy intervention to improve body image in adolescent girls. These findings indicate that a similar intervention for emerging adults would likely be efficacious. These results also suggest that health professionals should integrate discussions about SNS use into their treatment of body dissatisfaction and disordered eating. Recent research finds that less than $20 \%$ of participants in ED recovery have discussed the impacts of SNS with a therapist. ${ }^{65}$ Given the profound association between disordered eating and the three forms of SNS, it is important that these interrelations be integrated into clinical settings.

In addition, the current findings have potential policy implications. Participants were equally likely to use each SNS to seek social connection, yet more likely to use Snapchat or Instagram for passive purposes. Passive SNS use is linked to decrements in subjective well-being by way of social comparison. ${ }^{66}$ Educational campaigns promoting adaptive SNS usage should encourage users to avoid passive SNS use, highlight gains in social capital and connection made through active use, and inform users that information and images shared on SNS are frequently self-selected to be positive. $^{67}$

\section{Limitations and future directions}

While the current study provides novel information about differences in the three top SNS for young adults, it does come with limitations. We drew from a convenience sample of SNS users, although representative of use patterns for this demographic, ${ }^{32}$ and relied in their self-report, which may have not been fully accurate. Second, we are unable to draw causal inferences (i.e., we cannot determine whether individuals who engage in frequent body surveillance are drawn to applications such as Instagram and Snapchat, or if using these SNS platforms encourage more body surveillance). Moreover, at the time of data collection, there was no standardized measure of SNS uses and gratifications with items applicable to the three SNS. Future research exploring the integration of these theories should draw on a more comprehensive measure to quantify SNS uses and gratifications.

The current study also lacked information regarding potential confounding variables, such as family income, prior psychological trauma, or participant affective data. It is unclear why participants rated their SNS experience as positive or negative. A negative outlook may be unique to SNS experiences, or indicative of the lens everyday environments are viewed. SNS use has been linked to depression and low self-esteem in young adults. ${ }^{68}$ Therefore, it is possible that affect is driving the SNS negativity rating and model relationships. These mental health outcomes appear in the initial conceptualization of objectification theory, ${ }^{17}$ and have bidirectional influences with appearance-related comparison, body surveillance, ${ }^{69-71}$ and disordered eating tendencies. ${ }^{72}$

Data from this study provide empirical support for the inclusion of popular SNS platforms when examining interwoven influences of social comparison, objectification, and gratifications and uses theories on disordered eating out- comes. $^{3,24}$ Users of each platform experienced disordered eating tendencies that were accentuated by daily, subjectively negative SNS experiences and social-cognitive processes previously associated with such outcomes. This work highlights the need for increased awareness of the possible negative impacts of SNS, and the importance of examining SNS use in tandem with other factors contributing to disordered eating.

\section{Notes}

a. Potential participants were excluded for the following reasons: younger than $18(N=7)$, older than $24(N=55)$, prior ED diagnosis $(N=42)$, did not provide an answer to prior ED diagnosis question $(N=2)$, did not use SNS $(N=22)$, reported primarily using a social media platform other than Facebook, Snapchat, or Instagram $(N=81)$, did not self-identify as female $(N=1)$, completed less than $60 \%$ of the entire survey $(N=13)$, and failed the attention checks embedded within the survey $(N=134)$.

b. Daily time spent on SNS did not differ based on primary platform endorsed, $\chi^{2}(10)=16.88, p=0.08$, nor based on the primary reason for engaging with $\mathrm{SNS}, \chi^{2}(15)=12.42$, $p=0.65$. Participants spent the most time on the platform they primarily endorsed, and then, the remaining time on one of the other two platforms with equal distribution across Facebook, Instagram, and Snapchat, $\chi^{2}(2)=3.97, p=0.14$ for the secondmost frequently used platform and $\chi^{2}(2)=1.96, p=0.38$ for the third-most frequently used platform. The primary uses and gratifications sought by users differed significantly based on the primary platform endorsed, $\chi^{2}(6)=51.00, p<0.001$.

\section{Acknowledgments}

The authors thank Hannah Schindler, Britany Priore, and Yanet Ruvalcaba for their assistance in coding the qualitative responses in the pilot work related to this study.

\section{Author Disclosure Statement}

All authors declare that they have no conflicts of interest.

\section{References}

1. Fitzsimmons-Craft EE, Bardone-Cone AM, Bulik CM, et al. Examining an elaborated sociocultural model of disordered eating among college women: the roles of social comparison and body surveillance. Body Image 2014; 11 : 488-500.

2. Tylka TL, Sabik NJ. Integrating social comparison theory and self-esteem within objectification theory to predict women's disordered eating. Sex Roles 2010; 63:18-31.

3. Hesse-Biber S, Leavy P, Quinn CE, et al. The mass marketing of disordered eating and eating disorders: the social psychology of women, thinness and culture. Women's Studies International Forum 2006; 29:208-224.

4. Culbert KM, Racine SE, Klump KL. Research review: what we have learned about the causes of eating disorders-a synthesis of sociocultural, psychological, and biological research. Journal of Child Psychology and Psychiatry 2015; 56:1141-1164.

5. Fitzsimmons-Craft EE, Bardone-Cone AM, Wonderlich $\mathrm{SA}$, et al. The relationships among social comparisons, 
body surveillance, and body dissatisfaction in the natural environment. Behavior Therapy 2015; 46:257-271.

6. Saunders JF, Frazier LD. Body dissatisfaction in early adolescence: the coactive roles of cognitive and sociocultural factors. Journal of Youth and Adolescence 2017; 46:1246-1261.

7. Festinger L. A theory of social comparison processes. Human Relations 1954; 7, 117-140.

8. Jones AM, Buckingham JT. Self-esteem as a moderator of the effect of social comparison on women's body image. Journal of Social and Clinical Psychology 2005; 24:1164 1187.

9. Want SC. Meta-analytic moderators of experimental exposure to media portrayals of women on female appearance satisfaction: social comparisons as automatic processes. Body Image 2009; 6:257-269.

10. Paxton SJ, McLean SA. (2010). Treatment for body image disturbances. In Grilo CM, Mitchell JE, eds. The treatment of eating disorders. New York: Guilford, pp. 471-486.

11. Wood JV, Giordano-Beech M, Taylor KL, et al. Strategies of social comparison among people with low self-esteem: self-protection and self-enhancement. Journal of Personality and Social Psychology 1994; 67:713-731.

12. Fitzsimmons-Craft EE. Eating disorder-related social comparison in college women's everyday lives. International Journal of Eating Disorders 2017;50:893-905.

13. Lin LF, Kulik JA. Social comparison and women's body satisfaction. Basic and Applied Social Psychology 2002; 24:115-123.

14. Rancourt D, Schaefer LM, Bosson JK, et al. Differential impact of upward and downward comparisons on diverse women's disordered eating behaviors and body image. International Journal of Eating Disorders 2016; 49:519-523.

15. Lin L, Soby M. Appearance comparisons styles and eating disordered symptoms in women. Eating Behaviors 2016; 23:7-12.

16. McKinley NM, Hyde JS. The objectified body consciousness scale development and validation. Psychology of Women Quarterly 1996; 20:181-215.

17. Fredrickson BL, Roberts TA. Objectification theory: toward understanding women's lived experiences and mental health risks. Psychology of Women Quarterly 1997; 21: 173-206.

18. United Nations. (1995). Harmful traditional practices affecting the health of women and children: Fact Sheet No. 23. Geneva, Switzerland: UN Office of the High Commissioner for Human Rights (OHCHR).

19. Calogero RM, Tantleff-Dunn SE, Thompson J. (2011). Objectification theory: an introduction. In Calogero RM, Tantleff-Dunn SE, Thompson J, eds. Self-objectification in women: causes, consequences, and counteractions. Washington, DC: American Psychological Association, pp. 3-21.

20. Lindner D, Tantleff-Dunn S. The development and psychometric evaluation of the self-objectification beliefs and behaviors scale. Psychology of Women Quarterly 2017; 41: 254-272.

21. McEwan B. Retention and resources: an exploration of how social network resources related to university commitment. Journal of College Student Retention: Research, Theory Practice 2013; 15:113-128.

22. Fox J, Warber KM. Queer identity management and political self-expression on social networking sites: a co-cultural approach to the spiral of silence. Journal of Communication 2015; 65:79-100.
23. Nabi RL, Prestin A, So J. Facebook friends with (health) benefits? Exploring social network site use and perceptions of social support, stress, and well-being. Cyberpsychology, Behavior, and Social Networking 2013; 16:721-727.

24. Perloff RM. Social media effects on young women's body image concerns: theoretical perspectives and an agenda for research. Sex Roles 2014; 71:363-377.

25. Fardouly J, Diedrichs PC, Vartanian LR, et al.The mediating role of appearance comparisons in the relationship between media usage and self-objectification in young women. Psychology of Women Quarterly 2015; 39:447-457.

26. Bryant J, Miron D. Theory and research in mass communication. Journal of Communication 2004; 54:662-704.

27. Katz E, Blumler JG, Gurevitch M. (1974). The uses and gratifications approach to mass communication. Beverly Hills, CA: Sage.

28. Arnett JJ. Emerging adulthood: a theory of development from the late teens through the twenties. American Psychologist 2000; 55:469-480.

29. Sawyer SM, Azzopardi PS, Wickremarathne D, et al. The age of adolescence. The Lancet: Child and Adolescence 2018; 12:1-6.

30. Karazsia BT, Murnen SK, Tylka TL. Is body dissatisfaction changing across time? A cross-temporal meta-analysis. Psychological Bulletin 2017; 143:293-320.

31. Knight-McCord J, Cleary D, Grant N, et al. Journal of Undergraduate Ethnic Minority Psychology 2016; 2:21-25.

32. Pew Research Center (2017). Social media fact sheet. www.pewinternet.org/fact-sheet/social-media (accessed June 20, 2017).

33. Statista (2017). Reach of leading social media and networking sites used by teenagers and young adults in the United States as of February 2017. www.statista.com/ statistics/199242/social-media-and-networking-sites-used-byus-teenagers (accessed June 20, 2017).

34. Statista (2017b). Most popular social networks of teenagers in the United States from Fall 2012 to Spring 2017. www .statista.com/statistics/250172/social-network-usage-of-usteens-and-young-adults (accessed June 20, 2017).

35. Fardouly J, Vartanian LR. Negative comparisons about one's appearance mediate the relationship between Facebook usage and body image concerns. Body Image 2015; 12:82-88.

36. Mabe AG, Forney KJ, Keel PK. Do you "like" my photo? Facebook use maintains eating disorder risk. International Journal of Eating Disorders 2014; 47:516-523.

37. Vandenbosch L, Eggermont S. Understanding sexual objectification: a comprehensive approach toward media exposure and girls' internalization of beauty ideals, selfobjectification, and body surveillance. Journal of Communication 2012; 62:869-887.

38. Kim JW, Chock TM. Body image 2.0: associations between social grooming on Facebook and body image concerns. Computers in Human Behavior 2015; 48:331-339.

39. Tiggemann M, Slater A. NetTweens: the Internet and body image concerns in preteenage girls. The Journal of Early Adolescence 2014; 34:606-620.

40. Fardouly J, Willburger BK, Vartanian LR. (2017). Instagram use and young women's body image concerns and self-objectification: testing mediational pathways. New Media \& Society. [Epub ahead of print]; DOI:10.1177/ 1461444817694499.

41. Stice E, Marti CN, Rohde P. Prevalence, incidence, impairment, and course of the proposed DSM-5 eating dis- 
order diagnoses in an 8-year prospective community study of young women. Journal of Abnormal Psychology 2013; 122:445-457.

42. American Psychiatric Association. (2013). Diagnostic and Statistical Manual of Mental Disorders, 5th ed. Arlington, VA: American Psychiatric Publishing.

43. Keel PK, Brown TA. Update on course and outcome in eating disorders. International Journal of Eating Disorders 2010; 43:195-204.

44. Hummel AC, Smith AR. Ask and you shall receive: desire and receipt of feedback via Facebook predicts disordered eating concerns. International Journal of Eating Disorders 2015; 48:436-442.

45. Meier EP, Gray J. Facebook photo activity associated with body image disturbance in adolescent girls. $\mathrm{Cy}$ berpsychology, Behavior, and Social Networking 2014; 17:199-206.

46. Griffiths S, Murray SB, Krug I, et al. The contribution of social media to body dissatisfaction, eating disorder symptoms, and anabolic steroid use among sexual minority men. Cyberpsychology, Behavior, and Social Networking 2018; 21:149-156.

47. Marengo D, Longobardi C, Fabris MA, et al. Highly visual social media and internalizing symptoms in adolescence: the mediating role of body image concerns. Computers in Human Behavior 2018; 82:63-69.

48. Manago AM, Ward LM, Lemm KM, et al. Facebook involvement, objectified body consciousness, body shame, and sexual assertiveness in college women and men. Sex Roles 2015; 72:1-14.

49. Sheldon P, Bryant K. Instagram: motives for its use and relationship to narcissism and contextual age. Computers in Human Behavior 2016; 58:89-97.

50. Bayer JB, Ellison NB, Schoenebeck SY, et al. Sharing the small moments: ephemeral social interaction on Snapchat. Information, Communication \& Society 2016; 19:956977.

51. Piwek L, Joinson A. "What do they snapchat about?" Patterns of use in time-limited instant messaging service. Computers in Human Behavior 2016; 54:358-367.

52. Pittman M, Reich B. Social media and loneliness: why an Instagram picture may be worth more than a thousand Twitter words. Computers in Human Behavior 2016; 62: 155-167.

53. Grieve R. Unpacking the characteristics of Snapchat users: a preliminary investigation and an agenda for future research. Computers in Human Behavior 2017; 74:130-138.

54. Royal Society for Public Health. (2017). \#StatusOfMind: social media and young people's mental health and wellbeing.

55. Mintz LB, Betz NE. Prevalence and correlates of eating disordered behaviors among undergraduate women. Journal of Counseling Psychology 1988; 35:463-471.

56. Alhabash S, Ma M. A tale of four platforms: motivations and uses of Facebook, Twitter, Instagram, and Snapchat among college students? Social Media+ Society 2017; 3: $1-13$.

57. O'Brien KS, Caputi P, Minto R, et al. Upward and downward physical appearance comparisons: development of scales and examination of predictive qualities. Body Image 2009; 6:201-206.

58. Forbush KT, Wildes JE, Pollack LO, et al. Development and validation of the Eating Pathology Symptoms Inventory (EPSI). Psychological Assessment 2013; 25:859.
59. Whiting A, Williams D. Why people use SNS: a uses and gratifications approach. Qualitative Market Research: AnInternational Journal 2013; 16:362-369.

60. Kline RB. (1998). Structural equation modeling. New York: Guilford.

61. Hu LT, Bentler PM. Cutoff criteria for fit indexes in covariance structure analysis: conventional criteria versus new alternatives. Structural Equation Modeling: A Multidisciplinary Journal 1999; 6:1-55.

62. Garner DM, Olmsted MP, Bohr Y, et al. (1982). The Eating Attitudes Test: psychometric features and clinical correlates. Psychological Medicine 1982; 12:871-878.

63. Prichard I, McLachlan AC, Lavis T, et al. The impact of different forms of \#fistpiration imagery on body image, mood, and self-objectification among young women. Sex Roles 2017 [Epub ahead of print]; DOI: 10.1007/s11199017-0830-3.

64. McLean SA, Wertheim EH, Masters J, et al. A pilot evaluation of a SNS literacy intervention to reduce risk factors for eating disorders. International Journal of Eating Disorders 2017; 50:847-851.

65. Saffran K, Fitzsimmons-Craft EE, Kass AE, et al. Facebook usage among those who have received treatment for an eating disorder in a group setting. International Journal of Eating Disorders 2016; 49:764-777.

66. Verduyn P, Lee DS, Park J, et al. Passive Facebook usage undermines affective well-being: experimental and longitudinal evidence. Journal of Experimental Psychology: General 2015; 144:480-488.

67. Verduyn P, Ybarra O, Résibois M, et al. Do social network sites enhance or undermine subjective well-being? A critical review. Social Issues and Policy Review 2017; 11:274302.

68. Primack BA, Shensa A, Escobar-Viera CG, et al. Use of multiple SNS platforms and symptoms of depression and anxiety: a nationally-representative study among US young adults. Computers in Human Behavior 2017; 69:1-9.

69. Tiggemann M, McGill B. The role of social comparison in the effect of magazine advertisements on women's mood and body dissatisfaction. Journal of Social and Clinical Psychology 2004; 23:23-44.

70. Grabe S, Hyde JS, Lindberg SM. Body objectification and depression in adolescents: the role of gender, shame, and rumination. Psychology of Women Quarterly 2007; 31: 164-175.

71. Peat CM, Muehlenkamp JJ. Self-objectification, disordered eating, and depression: a test of mediational pathways. Psychology of Women Quarterly 2011; 35:441-450.

72. Byrne ME, Eichen DM, Fitzsimmons-Craft EE, et al. Perfectionism, emotion dysregulation, and affective disturbance in relation to clinical impairment in college-age women at high risk for or with eating disorders. Eating Behaviors 2016; 23:131-136.

Address correspondence to: Jessica F. Saunders Women's Research Institute of Nevada University of Nevada Las Vegas 4505 South Maryland Parkway Box 455083 Las Vegas, NV 89154

E-mail: jessica.saunders@unlv.edu 